\title{
Article \\ Low-Cost Multifunctional Vacuum Chamber for Manufacturing PDMS Based Composites
}

\author{
Ronaldo Ariati ${ }^{1}$, Flaminio Sales ${ }^{1}\left[\right.$, Verônica Noronha ${ }^{1}$, Rui Lima ${ }^{2}\left[\right.$ and João Ribeiro ${ }^{2,3, *}$ \\ 1 ESTiG School of Technology and Management of Bragança, Instituto Politécnico de Bragança, \\ 5300-252 Braganza, Portugal; a46685@alunos.ipb.pt (R.A.); ffflaminio@gmail.com (F.S.); \\ noronhaveronica@hotmail.com (V.N.) \\ 2 MEtRICs, Mechanical Engineering Department, Campus de Azurém, University of Minho, \\ 4800-058 Guimarães, Portugal; r1@dem.uminho.pt \\ 3 CIMO Mountain Research Center, Instituto Politécnico de Bragança, 5300-252 Braganza, Portugal \\ * Correspondence: jribeiro@ipb.pt
}

check for updates

Citation: Ariati, R.; Sales, F.; Noronha, V.; Lima, R.; Ribeiro, J. Low-Cost Multifunctional Vacuum Chamber for Manufacturing PDMS Based Composites. Machines 2022, 10, 92. https://doi.org/10.3390/ machines10020092

Academic Editor: Mark J. Jackson

Received: 29 October 2021

Accepted: 21 January 2022

Published: 25 January 2022

Publisher's Note: MDPI stays neutral with regard to jurisdictional claims in published maps and institutional affiliations.

Copyright: (C) 2022 by the authors. Licensee MDPI, Basel, Switzerland. This article is an open access article distributed under the terms and conditions of the Creative Commons Attribution (CC BY) license (https:// creativecommons.org/licenses/by/ $4.0 /)$.

\begin{abstract}
Polydimethylsiloxane (PDMS) is one of the best known elastomers and has been used in several areas of activity, due to its excellent characteristics and properties, such as biocompatibility, flexibility, optical transparency and chemical stability. Furthermore, PDMS modified with other materials promotes the desired changes to broaden its range of applications in various fields of science. However, the heating, mixing and degassing steps of the manufacturing process have not received much attention in recent years when it comes to blending with solid materials. For instance, PDMS has been extensively studied in combination with waxes, which are frequently in a solid state at room temperature and as a result the interaction and manufacturing process are extremely complex and can compromise the desired material. Thus, in this work it is proposed a multifunctional vacuum chamber (MVC) with the aim to improve and accelerate the manufacturing process of PDMS composites combined with additives, blends and different kinds of solid materials. The MVC developed in this work allows to control the mixing speed parameters, temperature control and internal pressure. In addition, it is a low cost equipment and can be used for other possible modifications with different materials and processes with the ability to control those parameters. As a result, samples fabricated by using the MVC can achieve a time improvement over $133 \%$ at the heating and mixing step and approximately $200 \%$ at the last degassing step. Regarding the complete manufacturing process, it is possible to achieve an improvement over 150\%, when compared with the conventional manufacturing process. When compared to maximum tensile strength, specimens manufactured using the MVC have shown a 39\% and 65\% improvement in maximum strain. The samples have also shown a $9 \%$ improvement in transparency at room temperature and $12 \%$ at a temperature of about $75{ }^{\circ} \mathrm{C}$. It should be noted that the proposed MVC can be used for other blends and manufacturing processes where it is desirable to control the temperature, agitation speed and pressure.
\end{abstract}

Keywords: manufacturing; PDMS composites; vacuum chamber; beeswax; project; polydimethylsiloxane; fabrication process; gravity casting

\section{Introduction}

Elastomers have become popularly known in several scientific areas in recent decades due to their excellent characteristics and properties, such as: flexibility, biocompatibility and corrosion resistance [1]. PDMS is, among the various existing elastomers one that has been receiving attention among researchers at different engineering fields [2,3]. PDMS is a mixture of linear polymers belonging to a group of silicones based on organic polymers. This material is non-toxic, non-flammable, and has excellent mechanical, thermal and chemical properties [4-6]. PDMS has been applied in several areas, as the use in electronics, 
microfluidics and biomedical devices has been reported [2,7-9]. The main characteristics of this material are its highly flexible [10], biocompatibility [11], optically transparent [12] and low cost. To improve mechanical, thermal, and optical properties, it is possible to mix waxes [13] or nanoparticles with PDMS [14], among other materials [15]. This makes material have a wide applicability and improvement of some aspects such as superhydrophobic surfaces, water repellent [16], anti-icing, self-cleaning [17] and antiscaling [18], among other surficial properties [15].

Manufacturing processes commonly used with PDMS are numerous, depending on the mix and current needs, and can be complex processes or the use of expensive or unavailable equipment [19-21]. Some of these processes are the inlaying method, which consists of dissolving the PDMS that has been cured by TEOS under bis and DOTDL catalysis, and the wax weight ratios were followed by an ultrasonic treatment. Subsequently, a piece of immaculate tissue was dipped into the mixture, forming a layer of the mixture on the tissue surface, leaving it superhydrophobic [22]. Other processes are carried out with the cured PDMS immersed in a bath of paraffin resulting in the impregnation of the paraffin in the reticulated network of the PDMS. Another method also represents mixing uncured PDMS with paraffin/organic solvent and curing agent. Another way to mix is to put the PDMS in a liquid state with molten paraffin and then add the curing agent followed by mixing [13]. However, to create superhydrophobic coatings the spray method is used, which is composed of PDMS, THF, beeswax and curing agent, after spraying on the surface it is necessary to raise the temperature to evaporate the THF and cure the mixture [23]. The method trivially used in the composition of mixtures with waxes is gravity casting, which consists of mixing PDMS and waxes, paraffin or beeswax, followed by heating and mixing to impregnate the elastomeric matrix, after this step add the curing agent, mix and pour into molds. The last step consists of the degassing process [24]. These processes can also be used for PDMS combination with other materials. For instance, the literature presents works with composites with the elastomer and additives, waxes, fibers, micro and nanoparticles [25-29]. However, the main problems pointed out are: As waxes are usually in their solid-state of matter at room temperature, mixing it with PDMS can cause some problems and require great attention.

Heating, as well as temperature control, are ideal for the perfect and efficient mixing to occur with the PDMS, which is in a liquid state, which is why the first heating step is so important [30-32]. In general, the mixtures should be agitated for a better distribution of the mixture and also more quickly. However, this agitation is often done manually due to the lack of equipment, simple or sophisticated, or even use some type of equipment for this step; however, it is a piece of high-cost equipment, not being convenient and available for all researchers [33-36]. Ffinally, to remove the air bubbles from the previous stirring step, as these two steps are not usually carried out simultaneously, it takes longer to remove the bubbles from the mixture, as the surface tension of the PDMS is high and it has not let them out. It should be noted that many studies have performed this step by taking at least 30 min by using conventional manufacturing methods [37-41].

The main objective of this work was to design, develop and manufacture a low-cost multifunctional vacuum chamber (MVC) capable of improving the large-scale production process of PDMS being mixed with other materials. In addition, a comparison was performed in with the conventional manufacturing method by means of optical and mechanical characterization. The majority of the conventional processes reported in the literature do not have control over the parameters at each step of the process, and as a result, it is likely the occurrence of potential errors and defects caused by the operators handling. It should be noted that the process does not have a standard, causing the process to be non-repeatable. The proposed MVC focuses on improving simultaneous steps, combining quality and time reduction, making the entire process efficient for large-scale production. 


\section{Materials and Methods}

For the manufacture of the multifunctional vacuum chamber, the following materials were used: $3 \mathrm{~mm}$ thick A36 steel sheet, $10 \mathrm{~mm}$ thick transparent acrylic sheet and the twocomponent poly (dimethylsiloxane) was selected, in which part A was selected, contains a prepolymer and part B is the catalyst to effect the cure.

The equipment used to control the motor rotation speed and the water bath temperature was a PWM 12 V DC (Diymore, Shenzhen, China) and STC-1000 (SHTROL, Xuzhou, China), respectively. The supports and covers were manufactured in 3D printing. The vacuum pump used was a two-stage piston with a flow capacity of $143 \mathrm{~L} / \mathrm{min}$ and a vacuum range of 13.53 psi. The vacuum chamber is stabilized when the pressure is down to $0.01 \mathrm{MPa}$ [42]. A two-component poly (dimethylsiloxane) was selected, in which part A contains a prepolymer and part B is the catalyst to effect the cure. The beeswax used was purchased from a local (Bragança, Portugal) beekeeper.

\subsection{Design}

The main mechanical objective for developing and manufacturing of these multifunctional vacuum chambers was to simplify and improve the efficiency of the process, as difficulties were reported during the mixing and degassing process, as well as the control of parameters during the manufacture of PDMS compounds [40]. The design of the multifunctional vacuum chamber was developed in the 3D CAD tool SolidWorks 2020, a license made available by the Polytechnic Institute of Bragança.

The developed multifunctional vacuum chamber is composed of an electric kettle and an electric perforation motor adapted inside the chamber to compose the heating and mixing steps of the composite, respectively. Vacuum pump and electronic controllers are listed on the outside. The electric kettle is used to heat the water bath using the joule effect to mix PDMS/wax at the melting temperature. The electric drill motor is used to carefully mix the liquid compound. The vacuum pump is used to partially remove the air from the chamber in order to reduce the internal pressure, in such a way, facilitating the exit of the gas bubbles formed during the mixing and pouring steps of the molds. Figure 1 illustrates, schematically, the elements of the system constituted for the simultaneous and sequential steps.

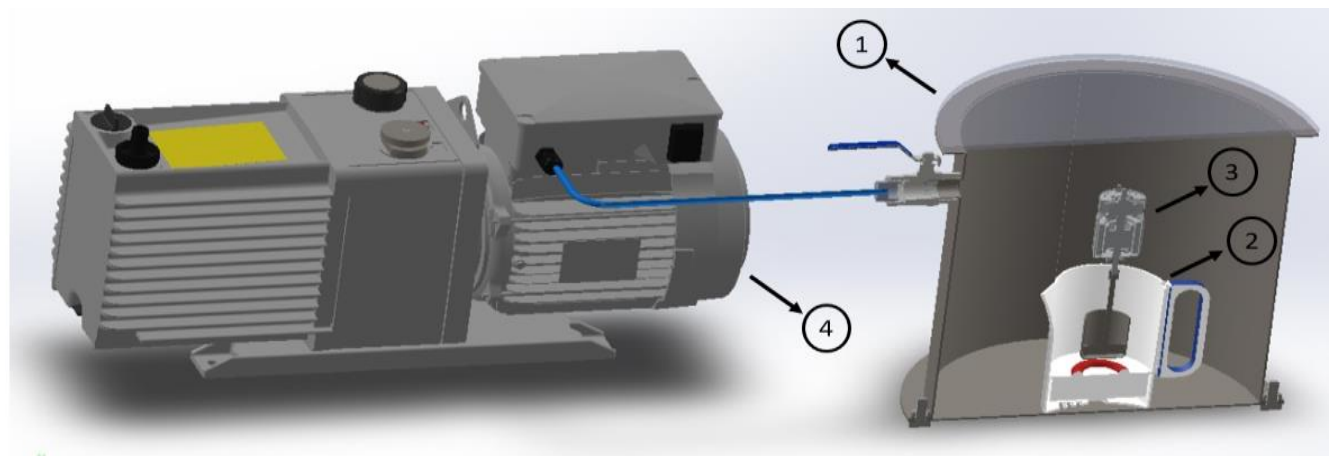

Figure 1. Multifunctional vacuum chamber project (1. Vacuum chamber; 2. Electric kettle; 3. Rotative motor and 4. Vacuum chamber).

The electrical system is essential for the correct functioning of the entire system, both for feeding the vacuum pump and for feeding the controllers. The voltage required to power the temperature controller and the PWM speed controller are $220 \mathrm{~V}$ and $12 \mathrm{~V}$, respectively. The PWM speed controller works with voltage and current variation to control the rotations per minute of the mixture, this equipment is connected to a power supply, lowering the voltage from $220 \mathrm{~V}$ AC to $12 \mathrm{~V} \mathrm{DC}$, whichever is used, feeds the motor of adapted drilling. The STC-1000 temperature controller (SHTROL, Xuzhou, China) works as an on and off switch of the electric kettle, so that when the electric kettle is turned on its operating power 
is always $100 \%$. The vacuum pump uses $220 \mathrm{~V}$ voltage to work properly. Figure 2 shows the functioning of the electrical system of the global system.

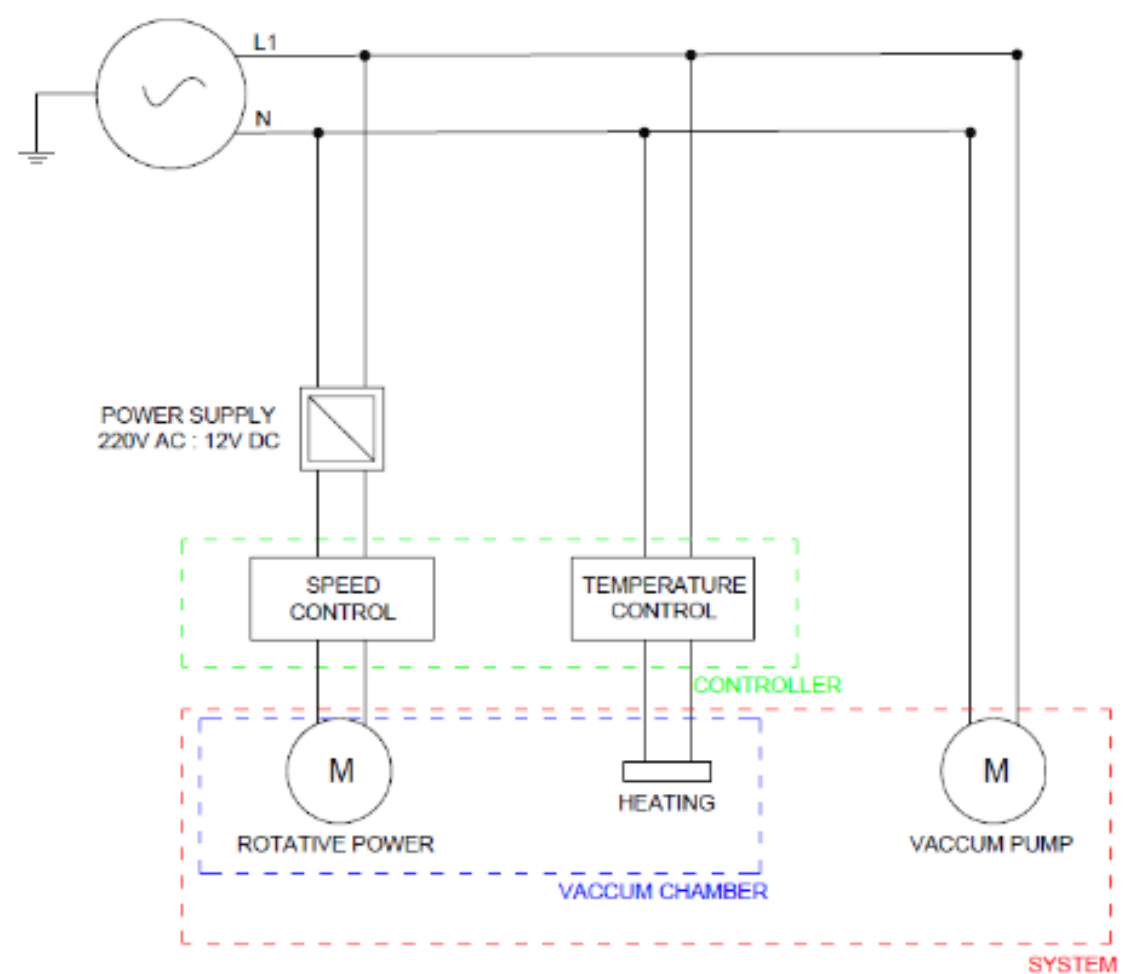

Figure 2. Electrical diagram of the power system for temperature, mixing and pressure controllers.

The main electrical diagram was developed to automate the process, being controllable outside the multifunctional vacuum chamber. Parameters that can be instantly adjusted are internal water temperature, compound agitation and negative atmospheric pressure. Thus, this multifunctional vacuum chamber is ideal for the manufacturing process of polymers and composites that require any heating, controlled mixing, negative atmospheric pressure or combinations of these parameters [20].

\subsection{Multifunctional Vacuum Chamber Manufacturing}

\subsubsection{Manufacturing of Mechanical Elements}

During the manufacturing process of the multifunctional vacuum chamber, several cutting processes were used, such as: hydraulic, laser and manual guillotine. On A36 steel plates with a thickness of $3 \mathrm{~mm}$, the shear cuts were performed using a hydraulic guillotine and manual cuts were necessary due to the complexity of the plates. The cuts by the mini 320 hydraulic guillotine were performed through the relative movement of a cutting punch against a die, in this case, the cut is simple with a square die, being the cylinder body of the chamber. The manual cuts, being the support rings of the upper and lower lid of the multifunctional vacuum chamber, were performed with the grinding wheel equipment with a cutting disc.

The laser cuts were performed on the acrylic sheet with the 2-AXIS Portlaser $x 252$ equipment (Portlaser, Pousa, Portugal) because it is easy, fast and accurate. This cut is more complex and with acrylic thickness of $10 \mathrm{~mm}$, the following cutting parameters were used: Speed $10.67 \mathrm{~mm} / \mathrm{s}$, Power $77.6 \mathrm{~W}$ and PPI 400. Due to the thick plate, it was difficult to cut and had to be executed several times for the laser to cut completely without damaging the plate.

At this stage of manufacturing the multifunctional vacuum chamber, a small handmade calendar available in the laboratory was used. The device is composed of a set of 
cylinders or rollers, with rotating movements and adjustable pressure. The use of this equipment was to bend the side of the MVC with the intention of forming a cylinder.

In this work, the MIG/MAG welding process was used to join the body of the multifunctional vacuum chamber to the support rings of the covers. The equipment used was the modular MIG 453 which uses the heat of an electrical arc continuously established between an electrode and the base metal to fuse the electrode tip and the base metal surface of the joint which is defined at $23.3 \mathrm{~V}$. The equipment was adjusted to weld the MVC body longitudinally and also to join the upper and lower ring together providing support for the acrylic cover and the lower part of the MVC.

Additive manufacturing technique that consists of developing the object graphically in computer software and subsequently manufactured by deposition of successive layers of material, which can be thermoplastics or other eutectic materials, on a heated platform. This process was used to fabricate the engine support with the metal cover and the support to connect the engine shaft to the mixing rod. The $3 \mathrm{D}$ printer used to manufacture the components is the Anet A8 Plus (Anet 3D Printer, Shenzhen, China).

\subsubsection{Assembly}

The multifunctional vacuum chamber took shape in each process performed in the previous item, being a logical assembly sequence. First, the union of the support rings of the lower and upper covers with the cylindrical body of the MVC was made, as shown in Figure 3a, followed by silicone above the weld for sealing. Then, the joint was made with screws and nuts for the cover and lower support with the aid of a silicone seal between them. To seal the acrylic lid and the upper support ring, a universal EPDM rubber adhesive tape was used between them. The parts manufactured in 3D printing consist of a box and a lid, both manufactured in PLA. The cover was fixed with support accessories also produced in PLA and by screws and nuts. The acrylic lid was cut again by the laser cutting equipment, and then a $1 / 4^{\prime \prime}$ thread was made to fix the vacuum gauge that is in the center of the lid in order to measure the internal pressure.
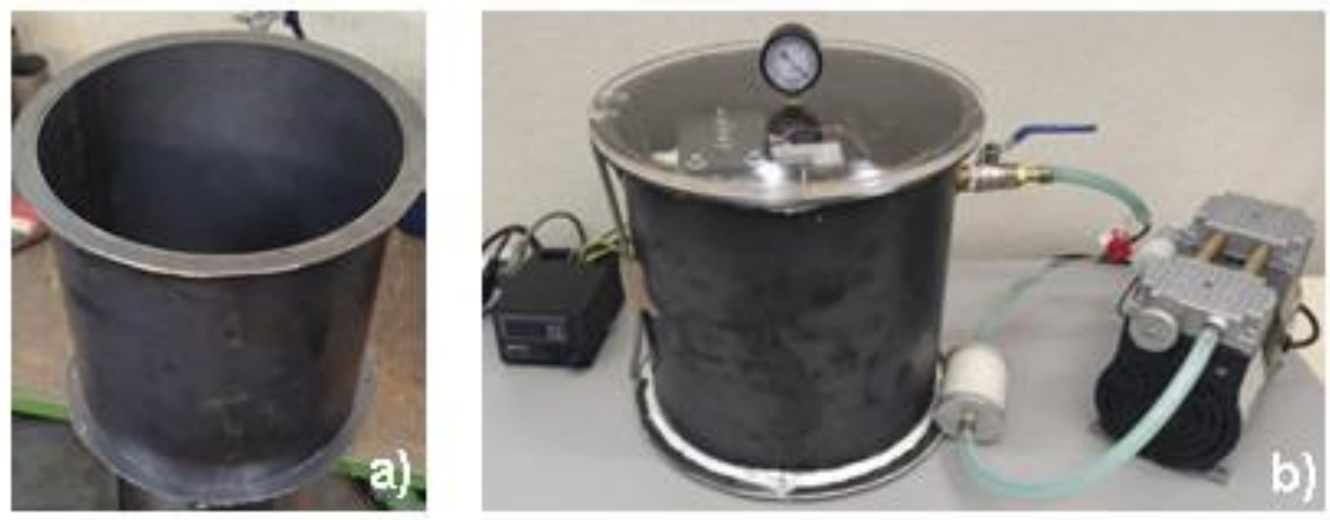

Figure 3. Fabrication and assembly of the Multifunctional vacuum chamber: (a) Welding support rings on the MVC body and (b) Complete set of vacuum chamber and accessories.

The PWM speed controller (Diymore, Shenzhen, China) is attached to the case made in $3 \mathrm{D}$ printing, is connected to a power supply which lowers the voltage to $12 \mathrm{~V} \mathrm{DC}$ and then power is supplied to the drilling motor positioned inside the MVC to make agitation. The STC-1000 temperature controller also located in the 3D-printed housing receives the voltage and transmits it directly to the electric kettle positioned inside the MVC. The vacuum pump is connected to a ball valve by a $1 / 4^{\prime \prime}$ gas hose making partial withdrawal of air from inside the multifunctional vacuum chamber. The complete system is shown in Figure 3b. 


\subsection{Testing Vacuum Chamber and Specimen Manufacturing}

After the manufacturing of the vacuum chamber, it was implemented some tests to evaluate the influence of the main operating parameters (heating, mixer and vacuum) in que quality of the composites and were manufactured tensile specimens using the vacuum chamber and by the conventional method.

The polydimethylsiloxane used to manufacture the specimens was Sylgard 184 (specification in Table 1) and the beeswax was obtained from a local beekeeper. For manufacturing, a two-component kit was required, one part being the polydimethylsiloxane prepolymer and the second part the crosslinking agent containing a mixture of vinyl- terminated polydimethylsiloxane and hydrogen. PDMS cure occurs when a catalyst is added under pure PDMS or already mixed with other substances through a reaction between the vinyl and hydrosilane groups [43].

The manufacture of PDMS with other additives, by a gravity casting process, requires 3 steps with parameters control to reach a homogeneous mixture, without bubbles and assuring the perfect interaction between PDMS and beeswax. The first step is the PDMS and beeswax mixing, in which it is necessary to heat the mixture, as the wax melts at approximately $65^{\circ} \mathrm{C}$ [44], being simultaneously stirred until the homogeneity of the mixing and speeding up the process. The second step is the catalyst (curing agent) addition to the mixture using a 10:1 w/w ratio, according to the manufacturer's instructions, followed by stirring until the mixture is homogeneous. The third and last step refers to removing the bubbles produced in the mixing and pouring the viscous mixture into the test molds.

Table 1. Properties of the PDMS and Beeswax [45-49].

\begin{tabular}{|c|c|c|}
\hline Property & PDMS & Beeswax \\
\hline Viscosity (base) & $5100 \mathrm{cP}$ & $0.1 \mathrm{cP}$ ratio \\
\hline Viscosity (mixed) & $3500 \mathrm{cP}$ & - \\
\hline Working time (pot life) & $1.5 \mathrm{~h}$ & - \\
\hline Cure time at $25^{\circ} \mathrm{C}$ & $48 \mathrm{~h}$ & - \\
\hline Density & $0.98 \mathrm{~g} / \mathrm{cm}^{3}$ & $0.95 \mathrm{~g} / \mathrm{cm}^{3}$ \\
\hline Kinematic viscosity $\left(80^{\circ} \mathrm{C}\right)$ & - & $8.2 \mathrm{mPa} \cdot \mathrm{s}$ \\
\hline Thermal conductivity & $0.27 \mathrm{~W} / \mathrm{m}^{\circ} \mathrm{K}$ & $0.20 \mathrm{~W} / \mathrm{m}^{\circ} \mathrm{K}$ \\
\hline
\end{tabular}

\subsubsection{Testing the Vacuum Chamber}

The temperature controller is connected to the electric kettle, heating the water contained inside the kettle through the joule effect. The STC-100 temperature controller equipment located outside the MVC is programmable, having 2 functions F1 and F2, where $\mathrm{F} 1$ is the specific temperature and F2 is the variation above and below this specific selected temperature. For testing liquids, the $\mathrm{F} 1$ value is $65^{\circ} \mathrm{C}$ and the $\mathrm{F} 2$ value is $0.1^{\circ} \mathrm{C}$. The liquid content is $500 \mathrm{~mL}$ for all liquids.

Some liquids were tested at this stage, looking for the smallest variation in the temperature range to increase the accuracy of constant heating during the melting and mixing process. The liquids are listed in Table 2 with their respective temperature ranges, along with the heating time and the cooling time, with water saturated with sugar being more suitable.

Table 2. Tests performed with different liquids checking the temperature range.

\begin{tabular}{cccc}
\hline Liquids & Range $\left({ }^{\circ} \mathbf{C}\right)$ & Heating Time & Cold Time \\
\hline Vegetable oil & $65-85$ & $1: 31 \mathrm{~min}$ & $21: 46 \mathrm{~min}$ \\
Detergent & $65-79.9$ & $1: 01 \mathrm{~min}$ & $18: 22 \mathrm{~min}$ \\
Water saturated sugar & $65-69.7$ & $00: 39 \mathrm{~s}$ & $5: 51 \mathrm{~min}$ \\
\hline
\end{tabular}

After the heating step of the composite, agitation is necessary for the wax to impregnate the PDMS matrix. To test the two methods, two metallic composite cups containing $20 \mathrm{~g}$ of 
PDMS and a proportion of $0.2 \mathrm{~g}$ of beeswax each were weighed. The heating and mixing process was carried out under the same conditions and times, at approximately $65^{\circ} \mathrm{C}$, but with temperature control available in MVC and in the conventional method there is no such control. The metallic cups are placed in a water bath, however, the metallic cup in the MVC is placed inside the electric kettle containing water saturated with sugar and the conventional method uses a double boiler inside a container containing water. The times that were performed for the tests are 1, 2, 5 and $7 \mathrm{~min}$ for the conventional method and 1,2 and $3 \mathrm{~min}$ for the method performed in the vacuum chamber in order to analyze the efficiency of the methods. Another test performed in this step is when the curing agent is added after the heating and mixing step and again returned to heat and mix with the curing agent, but the heat accelerates the PDMS curing process.

For the last stage of degassing, some tests were carried out. The maximum working pressure of the vacuum pump with the respective time was verified and the efficiency of the insulation of the multifunctional vacuum chamber was tested. First, the MVC was closed with the acrylic lid containing the lower-than-atmospheric pressure gauge and the time for the system to reach maximum working capacity was verified. In order to test the insulation of the united parts of the MVC, a test was carried out allowing the internal pressure to reach the maximum working capacity, so the ball valve was closed, trapping the internal pressure and verifying how long it would maintain full pressure.

The main steps to manufacture the composite PDMS/beeswax samples are: The first step is the mixing of the PDMS base polymer with the beeswax respecting the proportionality in weight. In the second step, it is necessary to heat the composites and carefully mix the two materials, when the mixture is homogeneous, the curing agent is added. Again, it is necessary to mix the composite, in the case of MVC it is already possible to do this step under vacuum action. Finally, the mixture is poured into the molds and degassed.

\subsubsection{Conventional Manufacturing Method of Specimens}

Samples were fabricated by combining PDMS with added beeswax (M_BW1\%). The preparation begins with weighing the PDMS and beeswax in the exact proportions for each mold, $5.5 \mathrm{~g}$ of the polymer and $0.05 \mathrm{~g}$ of wax were weighed. As PDMS and beeswax do not mix at room temperature, it is necessary to heat it to approximately $65{ }^{\circ} \mathrm{C}$ as shown in Figure 4a. The mixture was stirred with a metallic spatula, rotating clockwise for $7 \mathrm{~min}$ until the mixture was homogeneous. After this stirring process, the curing agent was added in a ratio of 10:1. Again, the stirring effect with the curing agent takes place for approximately $5 \mathrm{~min}$ and is then poured into the molds for testing. Finally, it was placed in a vacuum desiccator for $30 \mathrm{~min}$ to remove bubbles from the stirring and pouring process. The samples were left for $48 \mathrm{~h}$ at room temperature of $25^{\circ} \mathrm{C}$ to complete the curing process. Figure 5 a shows each step of the manufacturing process described above.
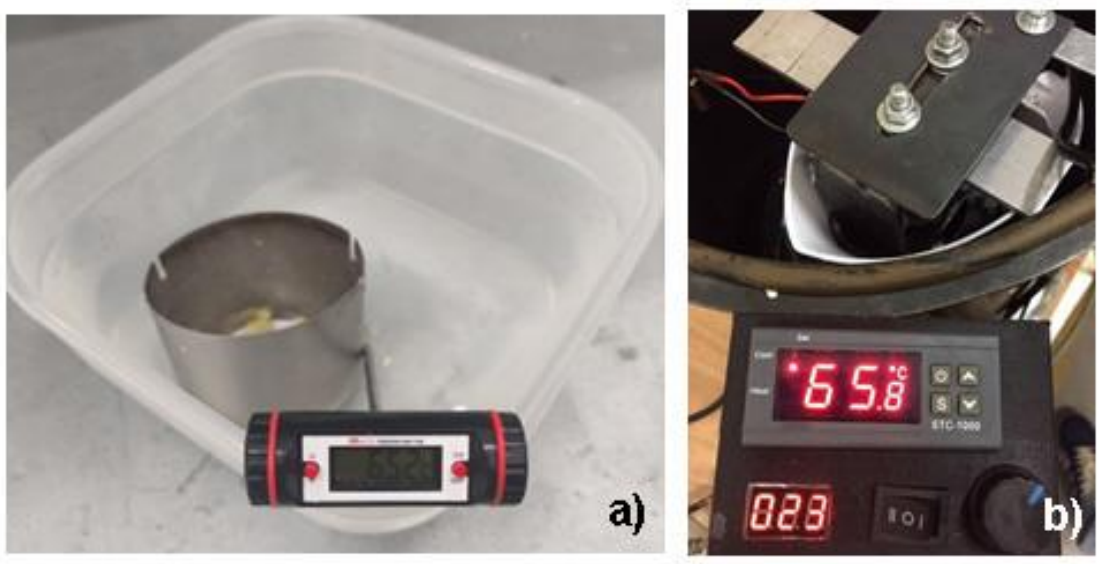

Figure 4. Procedure for mixing the PDMS and beeswax: (a) Conventional method and (b) Method using Multifunctional vacuum chamber. 


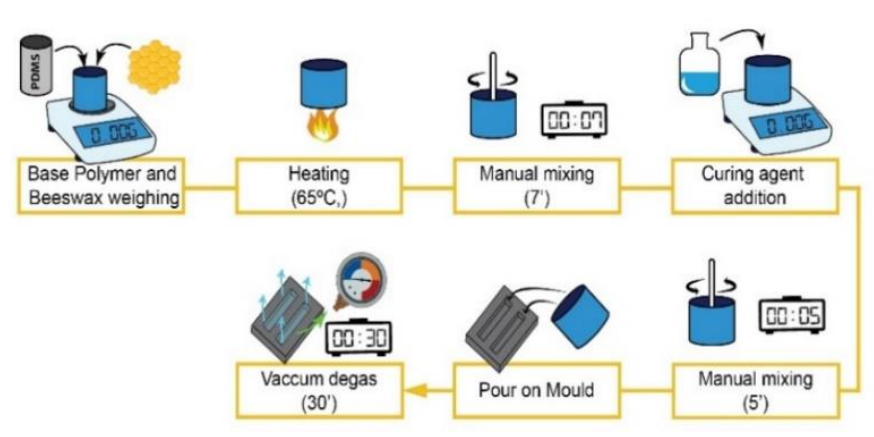

(a)

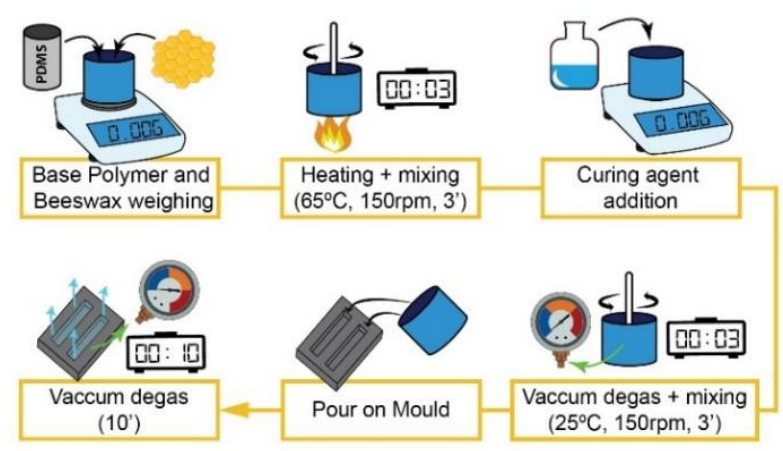

(b)

Figure 5. Manufacturing process: (a) conventional manufacturing method of specimens and (b) Specimens manufacturing using multifunctional vacuum chamber.

\subsubsection{Specimens Manufacturing Using the Developed Vacuum Chamber}

The manufacturing in the Multifunctional Vacuum Chamber holds control of some important parameters to improve the efficiency of the process, such as the temperature and agitation speed. In addition, it was able to do the degassing process while making agitation of the mixture inside the chamber. First, adding the beeswax (MVC_BW1\%) into the PDMS and weighing $5.5 \mathrm{~g}$ of the polymer and $0.05 \mathrm{~g}$ of beeswax as described in the previous process. The mixture was mixed using a mechanical stirrer with a speed controller, being stirred for 3 min with $23 \%$ of the maximum engine power until the mixture was homogeneous, controlling the temperature at approximately $65{ }^{\circ} \mathrm{C}$ as shown in Figure $4 \mathrm{~b}$. The second stage, the curing agent was added, followed by stirring in the MVC, for instantaneous degassing for approximately $3 \mathrm{~min}$ and poured into the molds to carry out the tests. The last step in the manufacturing process is to remove the few bubbles from shaking and pouring into the molds at MVC for only $10 \mathrm{~min}$. The samples were left for $48 \mathrm{~h}$ at room temperature of $25^{\circ} \mathrm{C}$ to complete the curing process. Figure $5 \mathrm{~b}$ shows each detailed step of the manufacturing process described above.

\subsection{Tensile Test}

Tensile tests were performed with 5 different specimens by means of a universal testing machine (Shimadzu, Quioto, Japan), using a cell-load of $10 \mathrm{kN}$ with an accuracy of $\pm 1 \%$ indicated test force (at $1 / 500$ to $1 / 1$ load cell rating) and the tensile test were accomplished with a displacement control. To carry out the test, a pre-test was first mounted on the machine, with a velocity of $5 \mathrm{~mm} / \mathrm{min}$, being adjusted until it reached a preload of 1 Newton and, from this point, the test was set up for a velocity of $500 \mathrm{~mm} / \mathrm{min}$ until it breaks. To prevent the slip of the samples during the test, a fine sandpaper was placed at the ends of the samples. The samples were fabricated and the test was performed in accordance with ASTM D412 [50].

\subsection{Spectrophotometry Test}

For the optical test, a Shimadzu UV-2600 spectrophotometer (Shimadzu, Quioto, Japan) was used. A sample of the conventional manufacturing method and a sample using the multifunctional vacuum chamber were used, the tensile samples were reused to perform this test. The wavelength range created for the equipment was between $200 \mu \mathrm{m}$ and $800 \mu \mathrm{m}$. Transmittance measurements were performed with the samples heated due to the composition of beeswax. To heat the samples, a water bath was used where the samples were immersed in the water. After heating for a few minutes, the samples were removed from the water, dried and placed in the spectrophotometer. 


\section{Results and Discussion}

The test results for the process of mixing, heating and degassing the PDMS and beeswax composites are much more qualitative than quantitative, so the analyses will be carried out to demonstrate the effects of each process step being controlled by temperature, time, agitation speed and pressure.

\subsection{Effect Heating}

The difficulty of this first stage of the process is temperature control, as the manufacturing processes described in the literature are carried out in a water bath without a temperature controller, thus losing process efficiency and negative results [20,33,51]. Temperature is the most important parameter for the homogeneity of the mixture, taking the beeswax to the liquid state of matter, facilitating and improving the interaction with the PDMS matrix. Figure 6 shows the action of temperature over time on the beeswax contained in PDMS, which stays at a temperature of $65^{\circ} \mathrm{C}$ for approximately $10 \mathrm{~min}$. This time depends on the amount of PDMS and beeswax that are directly proportional to time and temperature. As shown in Figure 6a, which contains PDMS and unheated beeswax over time, where the beeswax does not dissolve in the PDMS matrix. However, in Figure $6 \mathrm{~b}$ it is observed that after 1 min of heating, few signs of fusion begin to appear in the beeswax portions contained in the PDMS. In Figure $6 c$, one can more easily see the melting process of solid beeswax after 5 min of heating. Finally, in Figure $6 \mathrm{~d}$, after $10 \mathrm{~min}$ of heating at approximately $65^{\circ} \mathrm{C}$, the beeswax is completely in the liquid state of matter, making the interaction of beeswax in the PDMS matrix easier and more efficient.
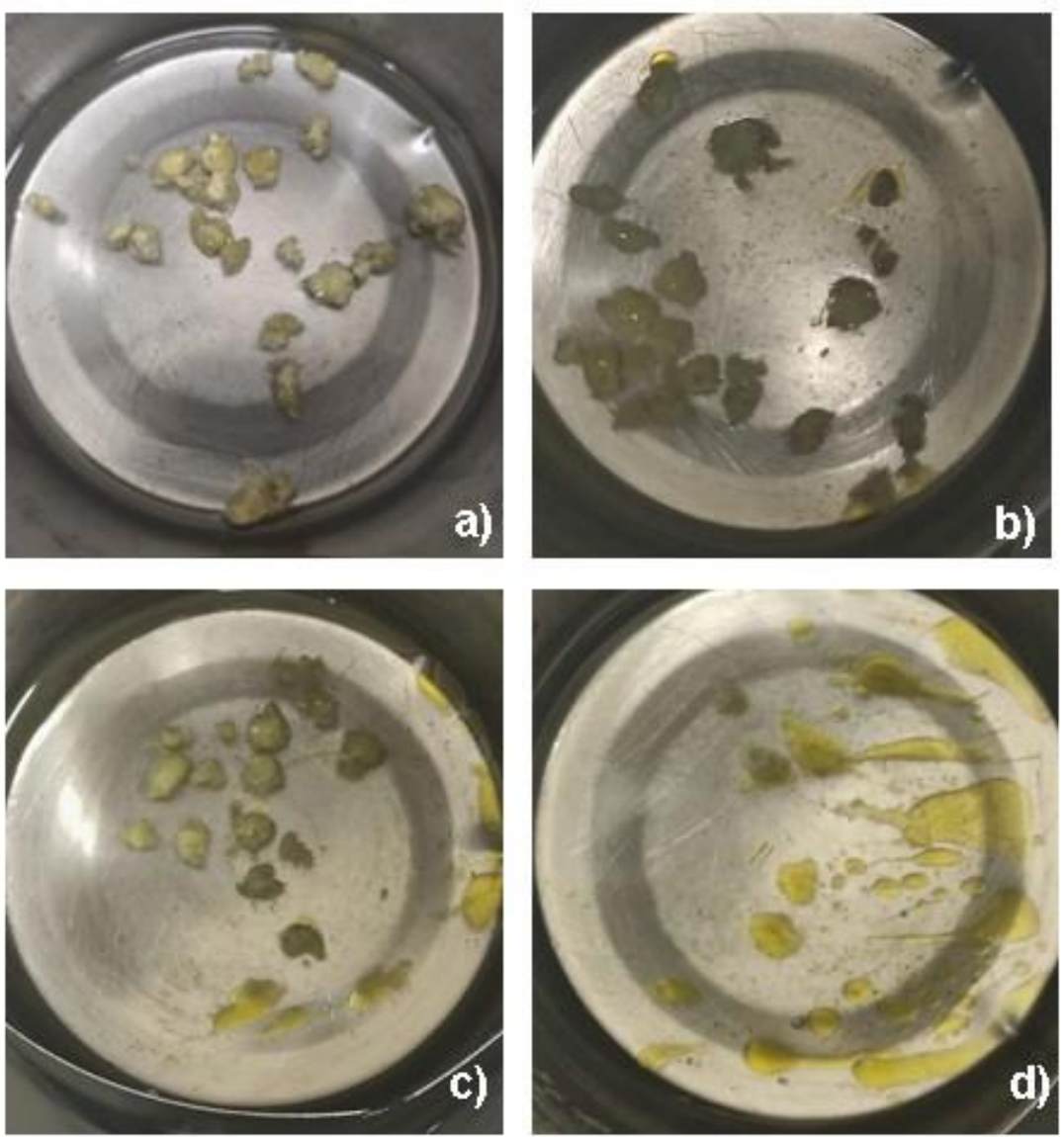

Figure 6. Effect of temperature on the PDMS and Beeswax mixture at $65^{\circ} \mathrm{C}$ over time: (a) No heating, (b) $1 \mathrm{~min}$, (c) $4 \mathrm{~min}$ and (d) $10 \mathrm{~min}$. 


\subsection{Effect Mixer}

After the essential heating process to improve the interaction of the mixture with the PDMS, the multifunctional vacuum chamber must be able to agitate the mixture so that it becomes homogeneous more quickly. Since these processes are carried out in different stages that are not simultaneous due to the unavailability of equipment [36,52-54]. The difficulty of the process defines that the mixture is manually agitated without speed control and agitation uniformity, thus having the delay and low efficiency of the process. The multifunctional vacuum chamber has the possibility of working with heating control and mixing agitation control simultaneously and can be used for other experiments with numerous variations of the desired parameters.

Figures 7 and 8 show the comparison in illustrative images of the manual stirring process and the automated stirring process performed in the multifunctional vacuum chamber. In Figure 7, manual agitation of the mixture composed of PDMS and beeswax was carried out along with constant heating at approximately $65^{\circ} \mathrm{C}$. In Figure 7 a circular agitation was carried out with a metal spatula with rectangular section in a clockwise direction for $1 \mathrm{~min}$ and show see that the wax is mostly in solid state. In the sequence of Figure $7 \mathrm{~b}$ the agitation continues in rotary motion for $2 \mathrm{~min}$ and we managed to repair a small decrease in the solid pieces of beeswax. The next image refers to the time of $4 \mathrm{~min}$ of constant clockwise stirring and show see a considerable decrease in the dissolved wax in the PDMS, but there are some small pieces of beeswax still in solid state as identified in Figure 7c. The last illustrative image being the Figure $7 \mathrm{~d}$ completely in the liquid state and mixed with the PDMS leaving the homogeneous mixture in the equivalent time of $7 \mathrm{~min}$.
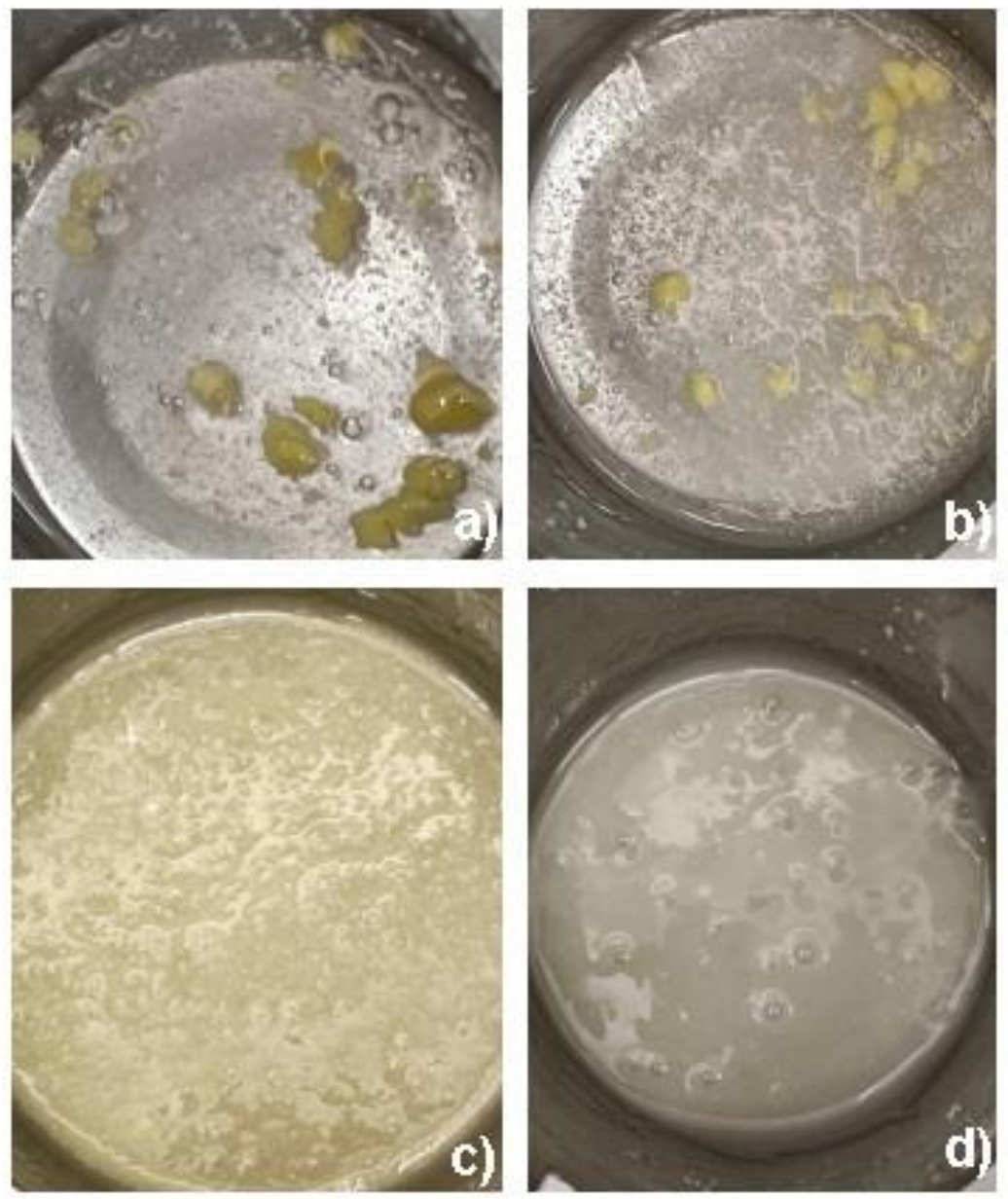

Figure 7. Manual mixing of PDMS and Beeswax at a constant temperature of $65^{\circ} \mathrm{C}$ with respect to time: (a) No stirring, (b) 2 min stirring, (c) 5 min stirring and (d) 7 min. 

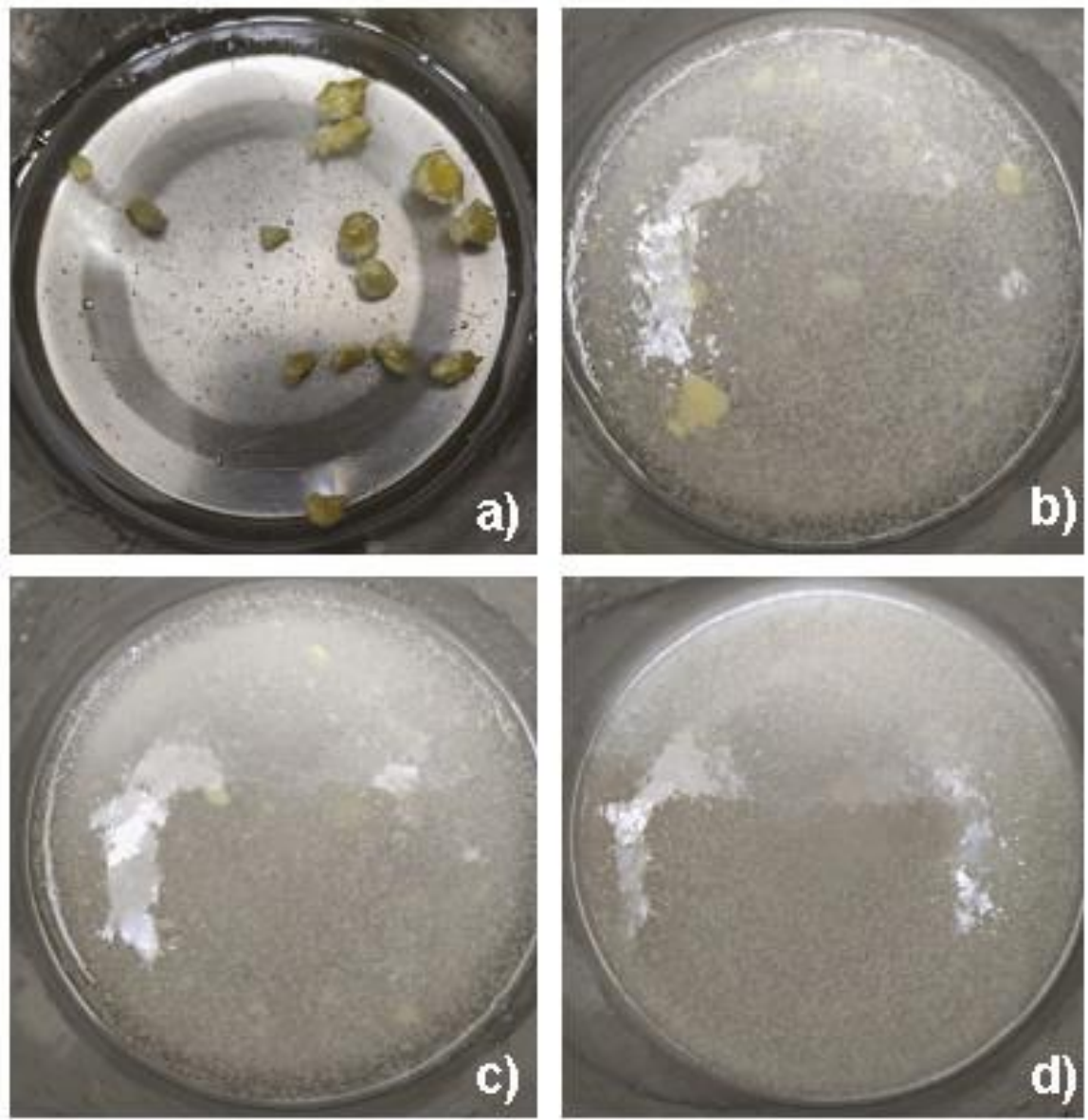

Figure 8. Automatic mixing of PDMS and Beeswax at a constant temperature of $65^{\circ} \mathrm{C}$ with respect to time: (a) No stirring, (b) 1 min stirring, (c) 2 min stirring and (d) 3 min.

The multifunctional vacuum chamber was developed with the aim of improving and speeding up the process steps for an effective and efficient series production. The mixing process in the multifunctional vacuum chamber was automated with the potential to control the rotations for minutes provided with the PWM speed controller. Figure 8 shows the dissolution of beeswax in polydimethylsiloxane as a function of time by the automated mixing method. Figure 8a illustrates the blending of polydimethylsiloxane with beeswax starches in the solid state of matter without stirring and heating for comparison. Figure $8 \mathrm{~b}$ shows the mixture made with $23 \%$ of the engine's maximum power for $1 \mathrm{~min}$ and heating to approximately $65^{\circ} \mathrm{C}$, identifying a rapid disaggregation of the beeswax in the PDMS. In the next illustrated image of Figure $8 \mathrm{c}$ after $2 \mathrm{~min}$ of stirring, the considerable decomposition of the beeswax can be seen.

In Figure 8d, the beeswax is completely dissolved in the polydimethylsiloxane matrix within 3 min of stirring. The comparison between Figures 7 and 8 shows that the use of this automated method causes a considerable reduction in the wax dissolution time in the PDMS. Constant controlled agitation refers to a better distribution of the wax and, consequently, faster, as the heat from the water is evenly dissipated throughout the composite mixture. The agitator obtains a mixing paddle that occupies a larger area than the process is done manually with a metal spatula. Compared to heating the composite without mixing and with mixing there is a considerable decrease in wax melting, however the time to completely melt the wax is $50 \%$ less. In Figures 7 and 8 , it is possible to see a difference in color and texture between the two composites; there is also a significant decrease in the mixing time of the methods, with the conventional method taking $7 \mathrm{~min}$ and the method using the vacuum chamber multifunctional costs a time of $3 \mathrm{~min}$. The composite mixed in the 
vacuum chamber with temperature and speed control improved by $133 \%$ in mixing time when compared to the conventional method.

\subsection{Effect of Vacuum}

Polydimethylsiloxane is present in works published in recent years due to its hydrophobicity, the fact that the molecular adhesion forces between water and the surface are weaker than the cohesion forces.

The high surface tension of polydimethylsiloxane creates a problem in the manufacture of specimens and does not allow the air bubbles generated in the stirring process to be removed, this fact happens at the interface between two chemical phases, making this surface layer of the liquid come to act as an elastic barrier. Atmospheric pressure creates pressure against the surface, making it difficult for the gases trapped inside the mixture to escape. In order to remove these inconvenient bubbles, a process called degassing is used. This process consists of applying negative pressure in relation to atmospheric pressure on the material in the liquid state, and by this pressure difference, the dissolved gases of the liquid compound are eliminated. These bubbles generated due to agitation of the mixture cause defects that can later cause distortion in the tests, causing results different from the real one.

Figure 9a demonstrates the last step of the process prepared by the conventional method in a time of 1:10 min at a pressure of $13.4 \mathrm{psi}$ in the vacuum gauge, with the existence of many bubbles on the upper surface of the mixture being visible, as shown in Figure $9 \mathrm{c}$. In addition, Figure $9 \mathrm{~b}$ shows the last step of the process developed by the new method employing the use of the multifunctional vacuum chamber in a time of 1:15 $\mathrm{min}$ at a pressure of $13.5 \mathrm{psi}$, with few bubbles being observed on the liquid surface as shown in the Figure $9 \mathrm{~d}$.
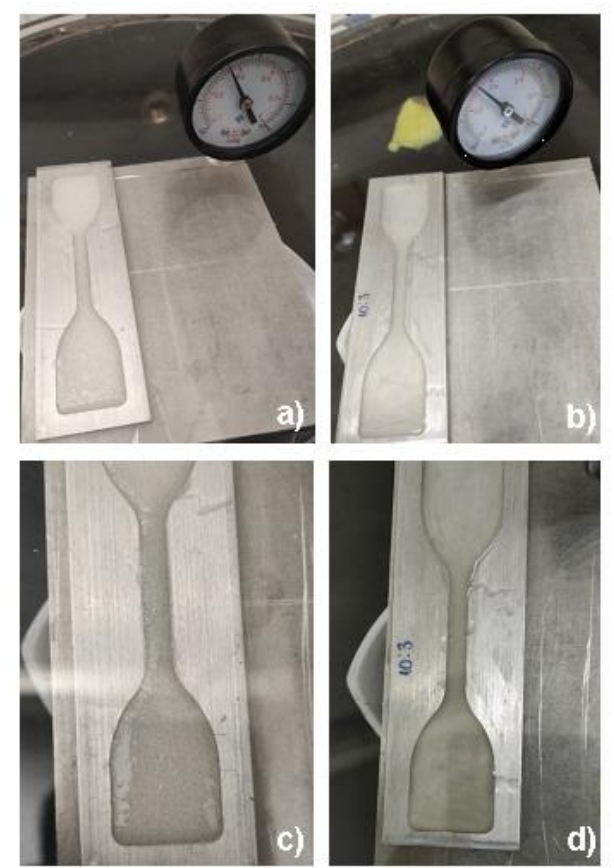

Figure 9. Comparison between the methods of the degassing process: (a) Conventional method in time 1:10 min and pressure $13.4 \mathrm{psi}$, (b) New method on MVC at time 1:15 min and pressure 13.5 psi. (c) Top surface bubble amount in conventional method, (d) Top surface bubble amount in new method in MVC.

It is possible to clearly observe the amount of bubbles existing on the surface, as shown in Figure 9c, produced by the conventional method due to the non-use of the vacuum action together with the final stages of the process to release the bubbles generated 
during the mixing step. However, in Figure $9 \mathrm{~d}$ there are few bubbles on the upper surface of the composite, which comes from the step in which the curing agent is added and mixed under the action of vacuum in the multifunctional vacuum chamber, thus carrying out the degassing step together with the curing agent mixing step resulting in reduced time. This new method, developed at MVC, takes approximately 3 min to degas, while other works reported in the literature are performed in a time equivalent to more than $40 \mathrm{~min}[39,41,51,55]$.

Figure 9 shows a comparison between the methods of the degassing process. (a) conventional method in time 1:10 min and pressure $13.4 \mathrm{psi}$, (b) new method on MVC at time 1:10 min and pressure 13.4 psi, (c) conventional method sample and (d) new method sample. It is possible to clearly observe the amount of bubbles existing on the surface, as shown in Figure 9c, produced by the conventional method due to not using the vacuum action together with the final steps of the process in order to release the wetness generated during the mixing step. However, in Figure $9 \mathrm{~d}$ there are few bubbles on the upper surface of the composite, which comes from the step in which the curing agent is added and mixed under the action of vacuum in the multifunctional vacuum chamber, thus making the degassing step together with the step of mixing the curing agent resulting in the shortening of time.

One way to try to avoid and speed up the process without bubbles or even small pieces of wax would be to carry out all the steps under the action of a vacuum, but in the tests carried out in this work when it is heated and already mixed with the curing agent, this heat works as a cure accelerator as at $80{ }^{\circ} \mathrm{C}$ the mixture cures completely in just $20 \mathrm{~min}$, according to the manufacturer, and there is no time to finish the process because the mixture starts its curing process quickly, resulting in incomplete melting of the beeswax and bubbles trapped inside the samples. Figure 10a shows small pieces of beeswax that did not melt and some bubbles that were not removed because the mixture quickly solidified. Due to this relevant factor, this process was divided into several steps as described in the materials and methods so that the mixture did not cure before the wax was in the liquid state of matter and the bubbles were removed. Figure $10 \mathrm{~b}$ shows a sample manufactured by different steps being heated and mixed, then added the curing agent and mixed at room temperature under vacuum action in the MVC and then poured into the molds under vacuum action again.
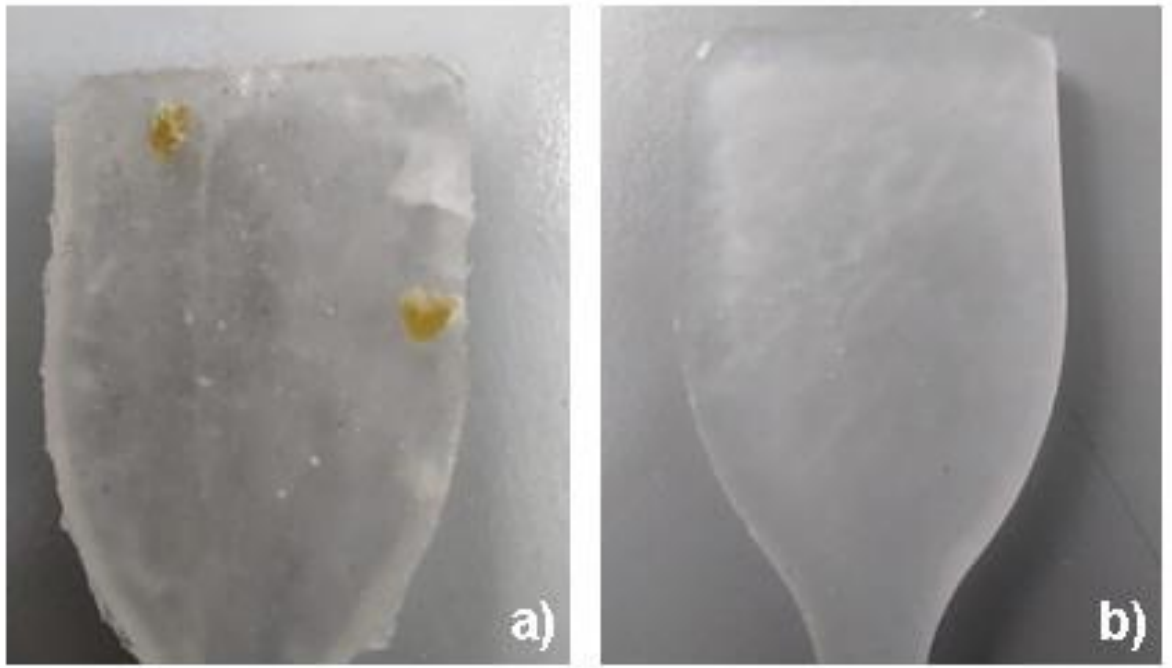

Figure 10. Samples after curing: (a) Sample with curing agent performed with heating and (b) Sample with curing agent performed without heat and with vacuum.

Figure 11 shows the uniformity of beeswax dispersion in the PDMS at a $100 \times$ scale. Figure 11a shows the sample performed by the conventional method and it is possible to notice that the wax particles are of non-uniform size. The sample produced by the 
multifunctional vacuum chamber has more uniformity in a certain region and smaller particles, as shown in Figure 11b, while the sample made by the conventional method shows disorder throughout the region and disorder in particle size. It is concluded from the optical microscope images that the samples manufactured using the multifunctional vacuum chamber show greater uniformity of beeswax in the PDMS.

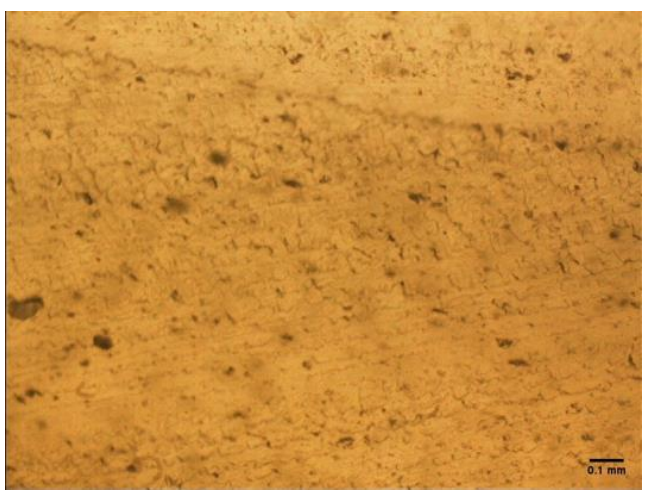

(a)

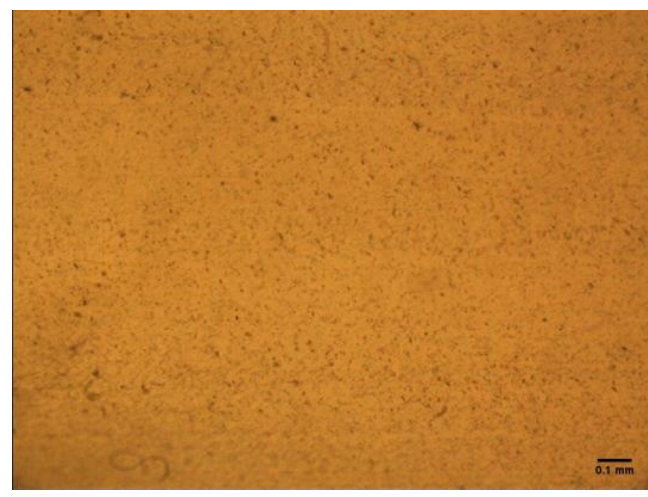

(b)

Figure 11. Images from optical microscope: (a) Conventional method and (b) method using the multifunctional vacuum chamber [15].

\subsection{Tensile Test}

The values obtained depend on the test parameters, and small variations in these parameters can lead to considerable distortions in the results. Thus, 5 specimens of each method and the arithmetic mean with the respective standard deviations were used. The stress versus strain results are shown in Figure 12.

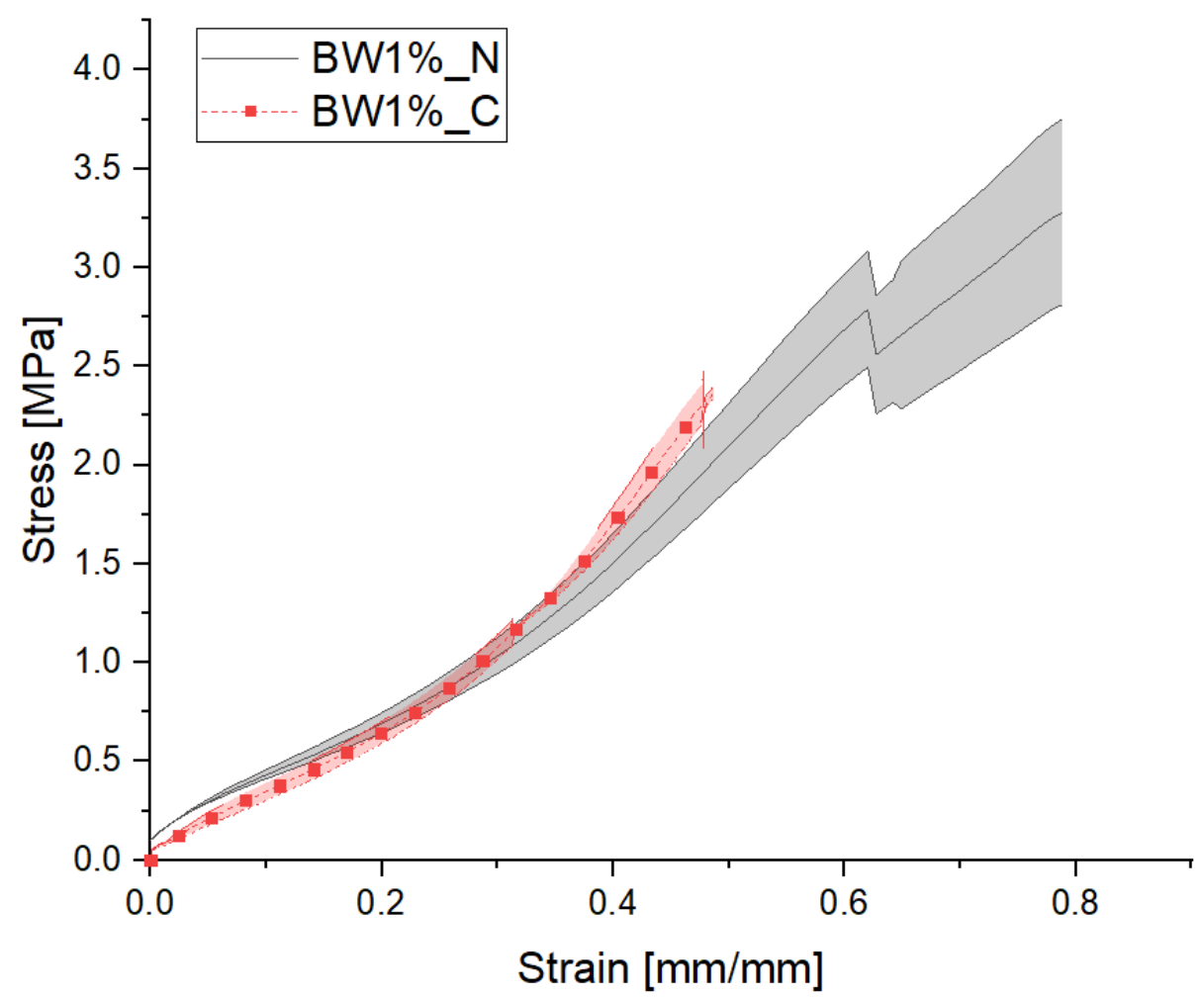

Figure 12. Engineering stress versus engineering strains. Comparison between the manufacturing methods counting that BW1\%_C is the curve of the samples manufactured by the conventional method and BW1\%_N is the samples manufactured using the MVC. 
The purpose of this graph is to perform a comparison between the samples from the two manufacturing methods and as a result to be able to observe the difference of the mechanical properties that the method using the MVC has provided. In Figure 12, a significant difference can be seen both in the maximum strength and in the maximum strain between the two groups of samples. The arithmetic average of the samples manufactured by the conventional method had lower tensile strength and less strain value when compared to the samples manufactured using the MVC.

The arithmetic average of the tensile strength of samples manufactured by the conventional method is approximately $2.36 \mathrm{MPa}$, which is consistent with the studies reported in the literature [15]. For the MVC samples, the tensile strength corresponds to 3.27 MPa. As a result, there was an improvement of the maximum tensile strength and maximum strain. The maximum tensile strength of the samples manufactured with the MVC improved about $39 \%$ when compared to the samples manufactured by the conventional method. When it comes to the maximum strain of the samples, the results were 0.48 and 0.81 for the samples manufactured by the conventional method and manufactured in the MVC, respectively, being consistent with the literature [15]. Hence, these results show that was an improvement bigger than $65 \%$ when compared to samples manufactured using MVC and manufactured using the conventional method.

In general, it can be seen that the mechanical properties of the MVC samples were improved when compared to the samples fabricated by the conventional method. This may be due to the organization of beeswax particles in the PDMS matrix being more evenly distributed.

\subsection{Spectrophotometry Test}

It is well known that pure PDMS has high transparency and as a result is a material with excellent optical and light propagation properties. However, beeswax is a material with low optical capacity at room temperature when compared to pure PDMS. When PDMS and beeswax are mixed, beeswax makes the material opaque at room temperature due to its low optical properties. However, when the composite is heated to high temperatures, the beeswax improves its optical properties making it as transparent as pure PDMS. Note that in this study, the comparison refers to samples manufactured by two different methods and temperatures.

In Figure 13 it is possible to verify and compare the effect of the MVC fabrication method and the conventional fabrication method in terms of transparency. The name of the curves with $C$ before the temperature is associated with the samples produced by the conventional method, and the curves with $\mathrm{N}$ correspond to the samples manufactured using MVC, for example BW1\%_C25 corresponds to the sample manufactured by the conventional method at a temperature of $25^{\circ} \mathrm{C}$. There was an improvement in the mixture of PDMS and beeswax manufactured with the MVC at room temperature when compared to the conventional method. The results were $51 \%$ and $65 \%$ of transmittance for the samples manufactured by the conventional method and the MVC, respectively. This improvement was approximately $9 \%$ increase of transparency of the MVC samples for the test performed at room temperature. When the samples were heated to $75{ }^{\circ} \mathrm{C}$, the obtained results were $71 \%$ and $81 \%$ of transmittance for the samples manufactured by the conventional method and the method using the MVC. This increase was about $12 \%$ in optical capacity, resulting in an improved transparency of the samples when fabricated with the proposed MVC.

Generally, the method using MVC to fabricate the samples has shown an improvement in optical properties, which may be due to the distribution of beeswax particles in the PDMS matrix and when the temperature increases, the beeswax changes from a solid state. to a liquid state leaving the sample translucent. 


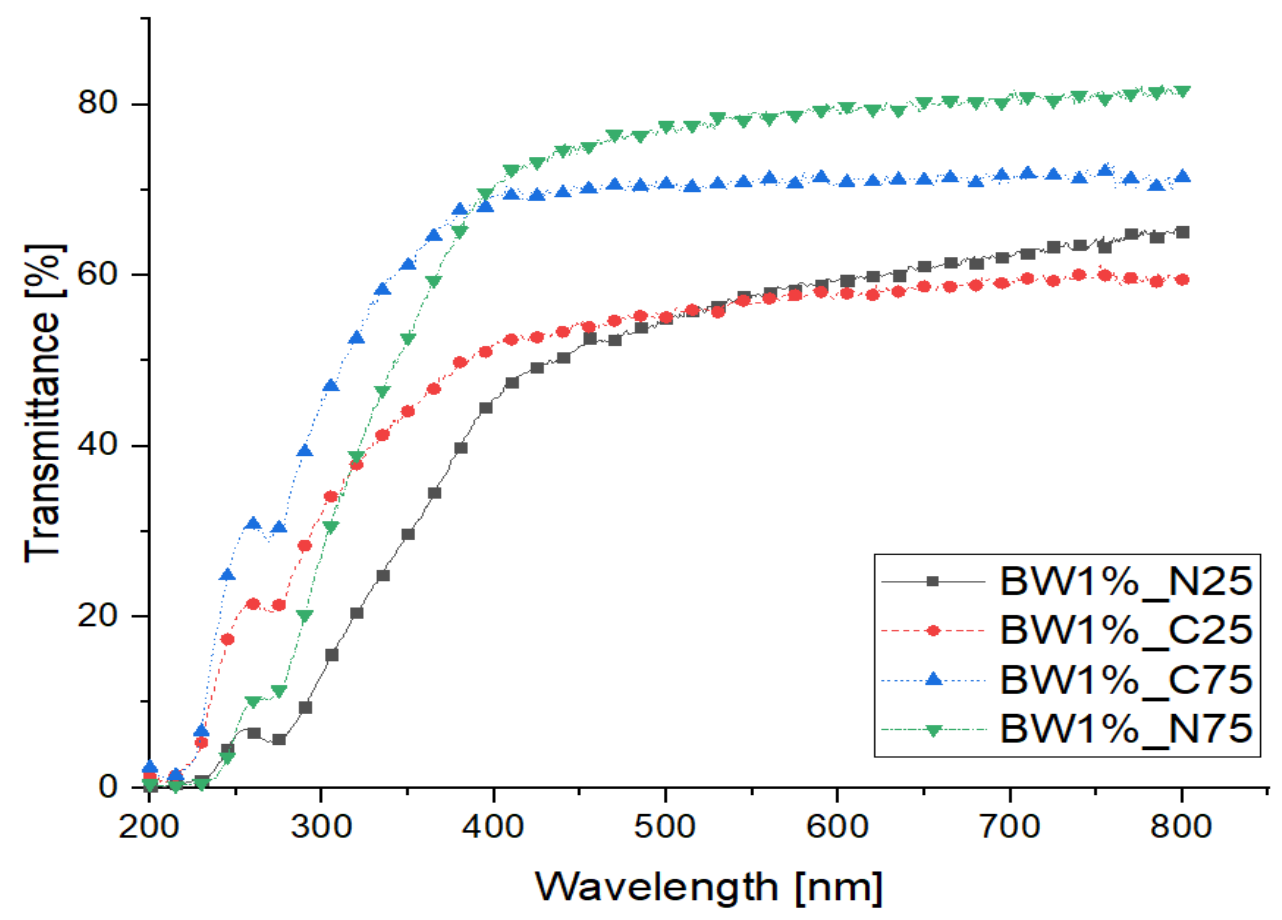

Figure 13. Wavelength versus transmittance for different temperatures and samples manufactured by means of the MVC (BW1\%_N25, BW1\%_N75) and the conventional method (BW1\%_C25, BW1\%_C75).

\section{Conclusions}

In this work a new method was proposed to improve the PDMS manufacturing process with different wax compositions that require heating, mixing and atmospheric pressure difference or even some of these simultaneous steps. Hence, in this study, it was developed a low-cost multifunctional vacuum chamber (MVC) to assist the manufacture of these composites and to accelerate the manufacture of composites without losing their main characteristics. Generally, these samples are most of the time manufactured by a simple conventional method without controlling the temperature, mixing and pressure parameters, so there is no repeatability and standard conditions for the process.

The proposed MVC played an important role for the composites manufacturing involving polymers, waxes and other additives. The MVC has the ability to program and control several features, such as the heating, mixing and negative pressure. By using the materials tested in this study, i.e., Poly (dimethylsiloxane) and beeswax, there was an improvement in all manufacturing steps. The main differences were the precision and the time, to perform the heating and mixing step, where the time have decreased by more than $133 \%$ making this step faster. Regarding the degassing step, an improvement of more than $200 \%$ was observed when compared to some works reported in the literature, due to the ability of the MVC to perform two actions simultaneously (mixing and vacuuming), making the step faster and more efficient. The samples have shown an improvement in mechanical properties such as maximum tensile strength equivalent to $39 \%$ and $65 \%$ in maximum strain. In the case of the optical properties, there was a $9 \%$ improvement at room temperature and $12 \%$ transparency when they were heated to approximately $75{ }^{\circ} \mathrm{C}$.

Generally, the proposed MVC has the ability to manufacture PDMS composites in a more efficient and faster way when compared to conventional methods. Additionally, it is a low-cost equipment as the price of all the MVC components was around $250 €$. It should be noted that the MVC can also be used for other applications that require the control of features such as heating, mixing and pressure. 


\begin{abstract}
Author Contributions: Conceptualization, J.R. and R.A.; methodology, F.S.; software, R.A.; validation, R.A., F.S. and V.N.; formal analysis, F.S.; investigation, R.A.; resources, J.R.; data curation, R.A.; writing —original draft preparation, R.A.; writing—review and editing, V.N. and R.L.; visualization, F.S.; supervision, J.R. and R.L.; project administration, J.R.; funding acquisition, R.L. All authors have read and agreed to the published version of the manuscript.
\end{abstract}

Funding: This research was partially funded by Portuguese national funds of FCT /MCTES (PIDDAC) through the base funding from the following research units: UIDB/00690/2020 (CIMO) and UIDB/04077/2020 (MEtRICs). The authors are grateful for the funding of ANI, FCT and CIMO through the projects POCI-01-02B7-FEDER-069844, and EXPL2021CIMO_01, respectively. The authors are also grateful for the partial funding of FCT through the projects EXPL/EMEEME/0732/2021, NORTE-01-0145-FEDER-030171 (PTDC/EMD-EMD/30171/2017) funded by COMPETE2020, NORTE2020, PORTUGAL2020, and FEDER.

Institutional Review Board Statement: Not applicable.

Informed Consent Statement: Not applicable.

Data Availability Statement: Not applicable.

Conflicts of Interest: The authors declare no conflict of interest.

\title{
References
}

1. Salazar-Hernández, C.; Salazar-Hernández, M.; Carrera-Cerritos, R.; Mendoza-Miranda, J.M.; Elorza-Rodríguez, E.; MirandaAvilés, R.; Mocada-Sánchez, C.D. Anticorrosive properties of PDMS-Silica coatings: Effect of methyl, phenyl and amino groups. Prog. Org. Coat. 2019, 136, 105220. [CrossRef]

2. Miranda, I.; Souza, A.; Sousa, P.; Ribeiro, J.; Castanheira, E.M.S.; Lima, R.; Minas, G. Properties and Applications of PDMS for Biomedical Engineering: A Review. J. Funct. Biomater. 2021, 13, 2. [CrossRef]

3. Teixeira, I.; Castro, I.; Carvalho, V.; Rodrigues, C.; Souza, A.; Lima, R.; Teixeira, S.; Ribeiro, J. Polydimethylsiloxane mechanical properties: A systematic review. AIMS Mater. Sci. 2021, 8, 952-973. [CrossRef]

4. Wolf, M.P.; Salieb-Beugelaar, G.B.; Hunziker, P. PDMS with designer functionalities-Properties, modifications strategies, and applications. Prog. Polym. Sci. 2018, 83, 97-134. [CrossRef]

5. Zhang, B.; Duan, J.; Huang, Y.; Hou, B. Double layered superhydrophobic PDMS-Candle soot coating with durable corrosion resistance and thermal-mechanical robustness. J. Mater. Sci. Technol. 2021, 71, 1-11. [CrossRef]

6. Chen, D.; Chen, F.; Hu, X.; Zhang, H.; Yin, X.; Zhou, Y. Thermal stability, mechanical and optical properties of novel addition cured PDMS composites with nano-silica sol and MQ silicone resin. Compos. Sci. Technol. 2015, 117, 307-314. [CrossRef]

7. Olmos, C.M.; Vaca, A.; Rosero, G.; Peñaherrera, A.; Perez, C.; de Sá Carneiro, I.; Vizuete, K.; Arroyo, C.R.; Debut, A.; Pérez, M.S.; et al. Epoxy resin mold and PDMS microfluidic devices through photopolymer flexographic printing plate. Sens. Actuators $B$ Chem. 2019, 288, 742-748. [CrossRef]

8. Faustino, V.; Rodrigues, R.O.; Pinho, D.; Costa, E.; Santos-Silva, A.; Miranda, V.; Amaral, J.S.; Lima, R. A Microfluidic Deformability Assessment of Pathological Red Blood Cells Flowing in a Hyperbolic Converging Microchannel. Micromachines 2019, 10, 645. [CrossRef]

9. Carvalho, V.; Gonçalves, I.; Lage, T.; Rodrigues, R.O.; Minas, G.; Teixeira, S.F.C.F.; Moita, A.S.; Hori, T.; Kaji, H.; Lima, R.A. 3D Printing Techniques and Their Applications to Organ-on-a-Chip Platforms: A Systematic Review. Sensors 2021, $21,3304$. [CrossRef]

10. Rajitha, G.; Dash, R.K. Optically transparent and high dielectric constant reduced graphene oxide (RGO)-PDMS based flexible composite for wearable and flexible sensors. Sens. Actuators A Phys. 2018, 277, 26-34. [CrossRef]

11. Souza, A.; Marques, E.; Balsa, C.; Ribeiro, J. Characterization of shear strain on PDMS: Numerical and experimental approaches. Appl. Sci. 2020, 10, 3322. [CrossRef]

12. Weng, M.; Chen, L.; Zhou, P.; Li, J.; Huang, Z.; Zhang, W. Low-voltage-driven, flexible and durable paraffin-polydimethylsiloxanebased composite film with switchable transparency. Chem. Eng. J. 2016, 295, 295-300. [CrossRef]

13. Shi, Y.; Hu, M.; Xing, Y.; Li, Y. Temperature-dependent thermal and mechanical properties of flexible functional PDMS/paraffin composites. Mater. Des. 2020, 185, 108219. [CrossRef]

14. Gong, X.; He, S. Highly Durable Superhydrophobic Polydimethylsiloxane/Silica Nanocomposite Surfaces with Good SelfCleaning Ability. ACS Omega 2020, 5, 4100-4108. [CrossRef]

15. Ariati, R.; Sales, F.; Souza, A.; Lima, R.A.; Ribeiro, J. Polydimethylsiloxane Composites Characterization and Its Applications: A Review. Polymers 2021, 13, 4258. [CrossRef]

16. Hong, S.; Wang, R.; Huang, X.; Liu, H. Facile one-step fabrication of PHC/PDMS anti-icing coatings with mechanical properties and good durability. Prog. Org. Coat. 2019, 135, 263-269. [CrossRef]

17. Zhang, W.; Jiang, S.; Lv, D. Fabrication and characterization of a PDMS modified polyurethane/Al composite coating with super-hydrophobicity and low infrared emissivity. Prog. Org. Coat. 2020, 143, 105622. [CrossRef] 
18. Gao, S.; Dong, X.; Huang, J.; Li, S.; Li, Y.; Chen, Z.; Lai, Y. Rational construction of highly transparent superhydrophobic coatings based on a non-particle, fluorine-free and water-rich system for versatile oil-water separation. Chem. Eng. J. 2018, 333, 621-629. [CrossRef]

19. Tarmizi, Z.I.; Maski, A.N.; Ali, R.R.; Jusoh, W.C.; Akim, A.; Eshak, Z.; Noor, S.; Ibrahim, N. Fabrication of hydrophilic silica coating varnish on pineapple peel fiber based biocomposite. Int. J. Integr. Eng. 2019, 7, 77-82. [CrossRef]

20. Pakzad, H.; Liravi, M.; Moosavi, A.; Nouri-Borujerdi, A.; Najafkhani, H. Fabrication of durable superhydrophobic surfaces using PDMS and beeswax for drag reduction of internal turbulent flow. Appl. Surf. Sci. 2020, 513, 145754. [CrossRef]

21. Ressel, J.; Seewald, O.; Bremser, W.; Reicher, H.P.; Strube, O.I. Self-lubricating coatings via PDMS micro-gel dispersions. Prog. Org. Coat. 2020, 146, 105705. [CrossRef]

22. Zhao, Y.; Liu, E.; Fan, J.; Chen, B.; Hu, X.; He, Y.; He, C. Superhydrophobic PDMS/wax coated polyester textiles with self-healing ability via inlaying method. Prog. Org. Coat. 2019, 132, 100-107. [CrossRef]

23. Weng, D.; Xu, F.; Li, X.; Li, Y.; Sun, J. Bioinspired photothermal conversion coatings with self-healing superhydrophobicity for efficient solar steam generation. J. Mater. Chem. A 2018, 6, 24441-24451. [CrossRef]

24. Sales, F.; Souza, A.; Ariati, R.; Noronha, V.; Giovanetti, E.; Lima, R.; Ribeiro, J. Composite Material of PDMS with Interchangeable Transmittance: Study of Optical, Mechanical Properties and Wettability. J. Compos. Sci. 2021, 5, 110. [CrossRef]

25. Torun, I.; Ruzi, M.; Er, F.; Onses, M.S. Superhydrophobic coatings made from biocompatible polydimethylsiloxane and natural wax. Prog. Org. Coat. 2019, 136, 105279. [CrossRef]

26. Tsao, C.W.; Lee, Y.P. Magnetic microparticle-polydimethylsiloxane composite for reversible microchannel bonding. Sci. Technol. Adv. Mater. 2016, 17, 2-11. [CrossRef]

27. Lee, J.H.; Kim, D.H.; Han, S.W.; Kim, B.R.; Park, E.J.; Jeong, M.G.; Kim, J.H.; Kim, Y.D. Fabrication of superhydrophobic fibre and its application to selective oil spill removal. Chem. Eng. J. 2016, 289, 1-6. [CrossRef]

28. Ren, X.; Jia, Y.; Lu, X.; Shi, T.; Ma, S. Preparation and characterization of PDMS-D2EHPA extraction gel membrane for metal ions extraction and stability enhancement. J. Membr. Sci. 2018, 559, 159-169. [CrossRef]

29. Yoo, B.Y.; Kim, B.H.; Lee, J.S.; Shin, B.H.; Kwon, H.; Koh, W.G.; Heo, C.Y. Dual surface modification of PDMS-based silicone implants to suppress capsular contracture. Acta Biomater. 2018, 76, 56-70. [CrossRef]

30. Paul, U.C.; Fragouli, D.; Bayer, I.S.; Athanassiou, A. Functionalized cellulose networks for efficient oil removal from oil-water emulsions. Polymers 2016, 8, 52. [CrossRef]

31. Celik, N.; Sahin, F.; Ruzi, M.; Yay, M.; Unal, E.; Onses, M.S. Blood repellent superhydrophobic surfaces constructed from nanoparticle-free and biocompatible materials. Colloids Surf. B Biointerfaces 2021, 205, 111864. [CrossRef] [PubMed]

32. Zhang, J.; Pu, G.; Dubay, M.R.; Zhao, Y.; Severtson, S.J. Repositionable pressure-sensitive adhesive possessing thermal-stimuli switchable transparency. J. Mater. Chem. C 2013, 1, 1080-1086. [CrossRef]

33. Zhai, G.; Qi, L.; He, W.; Dai, J.; Xu, Y.; Zheng, Y.; Huang, J.; Sun, D. Durable super-hydrophobic PDMS@SiO @WS $_{2}$ sponge for efficient oil/water separation in complex marine environment. Environ. Pollut. 2021, 269, 116118. [CrossRef] [PubMed]

34. Pan, Z.; Guan, Y.; Liu, Y.; Cheng, F. Facile fabrication of hydrophobic and underwater superoleophilic elastic and mechanical robust graphene/PDMS sponge for oil/water separation. Sep. Purif. Technol. 2021, 261, 118273. [CrossRef]

35. Li, D.; Xu, F.; Liu, Z.; Zhu, J.; Zhang, Q.; Shao, L. The effect of adding PDMS-OH and silica nanoparticles on sol-gel properties and effectiveness in stone protection. Appl. Surf. Sci. 2013, 266, 368-374. [CrossRef]

36. Smith, J.A.; Li, S.; Mele, E.; Goulas, A.; Engstrøm, D.; Silberschmidt, V.V. Printability and mechanical performance of biomedical PDMS-PEEK composites developed for material extrusion. J. Mech. Behav. Biomed. Mater. 2021, 115, 104291. [CrossRef]

37. Gezer, P.G.; Brodsky, S.; Hsiao, A.; Liu, G.L.; Kokini, J.L. Modification of the hydrophilic/hydrophobic characteristic of zein film surfaces by contact with oxygen plasma treated PDMS and oleic acid content. Colloids Surf. B Biointerfaces 2015, 135, 433-440. [CrossRef]

38. Liu, B.; Koh, D.; Wang, A.; Schneider, P.; Oh, K.W. Hermetic encapsulation of negative-pressure-driven PDMS microfluidic devices using paraffin wax and glass. Microsyst. Technol. 2018, 24, 2035-2043. [CrossRef]

39. Park, J.Y.; Song, H.; Kim, T.; Suk, J.W.; Kang, T.J.; Jung, D.; Kim, Y.H. PDMS-paraffin/graphene laminated films with electrothermally switchable haze. Carbon 2016, 96, 805-811. [CrossRef]

40. Souza, A.; Souza, M.S.; Pinho, D.; Agujetas, R.; Ferrera, C.; Lima, R.; Puga, H.; Ribeiro, J. 3D manufacturing of intracranial aneurysm biomodels for flow visualizations: Low cost fabrication processes. Mech. Res. Commun. 2020, 107, 103535. [CrossRef]

41. Potrich, C.; Lunelli, L.; Cocuzza, M.; Marasso, S.L.; Pirri, C.F.; Pederzolli, C. Simple PDMS microdevice for biomedical applications. Talanta 2019, 193, 44-50. [CrossRef] [PubMed]

42. Ye, X.; Liu, H.; Ding, Y.; Li, H.; Lu, B. Research on the cast molding process for high quality PDMS molds. Microelectron. Eng. 2009, 86, 310-313. [CrossRef]

43. Panou, A.I.; Papadokostaki, K.G.; Tarantili, P.A.; Sanopoulou, M. Effect of hydrophilic inclusions on PDMS crosslinking reaction and its interrelation with mechanical and water sorption properties of cured films. Eur. Polym. J. 2013, 49, 1803-1810. [CrossRef]

44. Bernal, J.L.; Jiménez, J.J.; Del Nozal, M.J.; Toribio, L.; Martín, M.T. Physico-chemical parameters for the characterization of pure beeswax and detection of adulterations. Eur. J. Lipid Sci. Technol. 2005, 107, 158-166. [CrossRef]

45. The Dow Chemical Company. SYLGARD ${ }^{\mathrm{TM}} 184$ Silicone Elastomer FEATURES \& BENEFITS 2017. Available online: https://www. dow.com/content/dam/dcc/documents/en-us/productdatasheet/11/11-31/11-3184-sylgard-184-elastomer.pdf?iframe=true (accessed on 28 October 2021). 
46. Wang, Z. Polydimethylsiloxane Mechanical Properties Measured by Macroscopic Compression and Nanoindentation Techniques. Master's Thesis, University of South Florida, Tampa, FL, USA, 2011.

47. Amin, M.; Putra, N.; Kosasih, E.A.; Prawiro, E.; Luanto, R.A.; Mahlia, T.M.I. Thermal properties of beeswax/graphene phase change material as energy storage for building applications. Appl. Therm. Eng. 2017, 112, 273-280. [CrossRef]

48. Bucio, A.; Moreno-Tovar, R.; Bucio, L.; Espinosa-Dávila, J.; Anguebes-Franceschi, F. Characterization of Beeswax, Candelilla Wax and Paraffin Wax for Coating Cheeses. Coatings 2021, 11, 261. [CrossRef]

49. Smitha Alex, A.; Rajeev, R.S.; Krishnaraj, K.; Sreenivas, N.; Manu, S.K.; Gouri, C.; Sekkar, V. Thermal protection characteristics of polydimethylsiloxane-organoclay nanocomposite. Polym. Degrad. Stab. 2017, 144, 281-291. [CrossRef]

50. ASTM D 412-06a; Standard Test Method for Tensile Properties of Vulcanized Rubber and Thermoplastic Elastomers. ASTM: West Conshohocken, PA, USA, 2018.

51. He, X.; Wang, T.; Li, Y.; Chen, J.; Li, J. Fabrication and characterization of micro-patterned PDMS composite membranes for enhanced ethanol recovery. J. Membr. Sci. 2018, 563, 447-459. [CrossRef]

52. Maram, S.K.; Barron, B.; Leung, J.C.K.; Pallapa, M.; Rezai, P. Fabrication and thermoresistive behavior characterization of three-dimensional silver-polydimethylsiloxane (Ag-PDMS) microbridges in a mini-channel. Sens. Actuators A Phys. 2018, 277, 43-51. [CrossRef]

53. Zhou, L.; Zhuang, G.; Li, G. A facile method for the fabrication of glass-PDMS-glass sandwich microfluidic devices by sacrificial molding. Sens. Actuators B Chem. 2018, 261, 364-371. [CrossRef]

54. Wang, L.; Lin, C.; Yang, L.; Zhang, J.; Zheng, J. Preparation of nano/micro-scale column-like topography on PDMS surfaces via vapor deposition: Dependence on volatility solvents. Appl. Surf. Sci. 2011, 258, 265-269. [CrossRef]

55. Adrees, M.; Iqbal, S.S.; Ahmad, A.; Jamshaid, F.; Haider, B.; Khan, M.H.; Khan, R.; Zahid Butt, M.T.; Bahadar, A. Characterization of novel polydimethylsiloxane (PDMS) and copolymer polyvinyl chloride-co-vinyl acetate (PVCA) enhanced polymer blend membranes for $\mathrm{CO}_{2}$ separation. Polym. Test. 2019, 80, 106163. [CrossRef] 